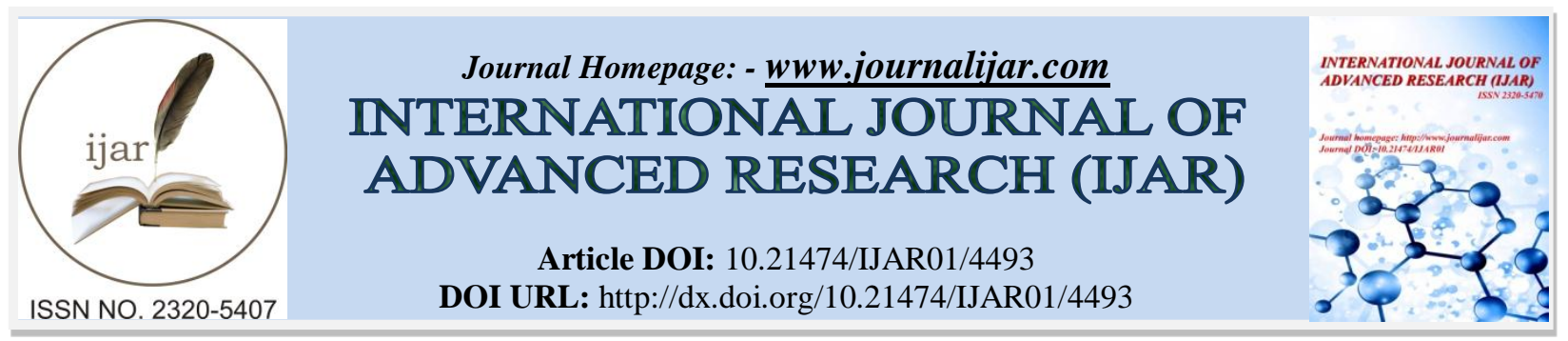

RESEARCH ARTICLE

\title{
ATTENUATION OF CARDIOVASCULAR RESPONSE DURING DIRECT LARYNGOSCOPY AND INTUBATION: A COMPARATIVE STUDY BETWEEN FENTANYL, LIGNOCAINE AND PLACEBO DURING GENERAL ANAESTHESIA
}

\section{Dr. Jyothsna Yadav .C ${ }^{1}$, Dr. Abhishek Vuppala ${ }^{2}$ and Dr. Roopa Kotha ${ }^{1}$.}

1. Assistant Professor, Department Of Anaesthesiology, Maheshwara Medical College And Hospital, Patancheru, Sangareddy, Telangana.

2. Senior Resident, Department Of Anaesthesiology, Gandhi Medical College, Hyderabad, Telangana.

\section{Manuscript Info}

\section{Manuscript History}

Received: 15 April 2017

Final Accepted: 17 May 2017

Published: June 2017

Key words:-

Fentanyl, Lignocaine, Cardiovascular response, General Anaesthesia

\section{Abstract}

Aims and Objectives: The aim of this study was to compare Fentanyl, Lignocaine and Placebo for attenuation of cardiovascular response to direct laryngoscopy and intubation during General Anaesthesia.

Methodology: After obtaining ethical committee approval and taking written informed consent from patients this study was done at Maheshwara medical college \& hospital in 75 patients of ASA grade I aged between 25-45 years coming for elective surgical procedures.

The patients were allocated into three groups of 25 each:

Group $\mathbf{F}$ - Fentanyl $2 \mu \mathrm{g} / \mathrm{kg}$ body weight

Group L - Lignocaine $1.5 \mathrm{mg} / \mathrm{kg}$ body weight

Group $\mathbf{N}$ - Normal saline $3 \mathrm{ml}$ as placebo

Observation and Results:

The heart rate, systolic and diastolic blood pressure responses during laryngoscopy and intubation have shown significant difference with fentanyl and lignocaine when compared with the placebo group.

Conclusion:

This study confirms that Fentanyl attenuates both heart rate and blood pressure responses to laryngoscopy and intubation, whereas with Lignocaine blood pressure was effectively controlled than heart rate.

Copy Right, IJAR, 2017,. All rights reserved.

\section{Introduction:-}

Direct laryngoscopy and endotracheal intubation are integral parts of day to day anaesthetic technique in modern anaesthesia. Laryngoscopy and tracheal intubation frequently induce a cardiovascular stress response characterized by hypertension, tachycardia, arrhythmias and increased serum concentrations of catecholamines which are transient and are considered innocuous in patients with normal cardiovascular status. Hypertensive response with Laryngoscopy and endotracheal intubation was first ${ }^{1}$ described by Reid and Brace in 1940. This hypertensive response may be harmful to patients with cardiovascular disease, increased intracranial pressure, or anomalies of cerebral vessels.

Various drugs and techniques have been used for attenuation of response to laryngoscopy and intubation $2,3,4,5$. They are topical anaesthesia of oropharynx (viscous lignocaine), laryngotracheal instillation of lignocaine prior to 
intubation, intravenous lignocaine, adrenergic blocking drugs (either alpha or beta blockers), vasodilators like hydralazine, sodium nitroprusside, nitroglycerine, deep inhalational anaesthesia, intravenous opioids etc. ${ }^{6,7,8}$. Amongst the recommended procedures intravenous lignocaine or fentanyl appear to be better options ${ }^{10}$.

Lignocaine is an amide local anaesthetic which has a rapid onset of action, exerts peak hemodynamic effects within one minute. It was proved ideal for control of hemodynamic sequelae, associated with laryngoscopy and intubation $^{11}$. Fentanyl is a potent, synthetic narcotic analgesic with a rapid onset and short duration of action. It is extremely lipid soluble, has a low molecular weight and is a synthetic opioid agonist which is popularly used as intravenous analgesic supplement, as a component of balanced anaesthesia and neuroleptic analgesia and also as a sole anaesthetic. It is 75 to 125 times more potent than morphine as an analgesic ${ }^{12}$. After intravenous administration, onset of effect is in 1-2 minutes, and the duration is for 1 hour. Consequently it has been proved ideal for control of hemodynamic sequelae, associated with laryngoscopy and intubation.

\section{Aim and Objectives:-}

The aim and objective of this study was to compare Fentanyl, Lignocaine, and Placebo for the attenuation of cardiovascular response to direct laryngoscopy and intubation during General Anaesthesia.

\section{Materials and Methods:-}

This study was carried out in the department of Anaesthesiology at Maheshwara medical college and hospital, Sangareddy during a period of one year (February 2016- February 2017).75 adult patients who were posted for elective surgical procedure under general anaesthesia requiring endotracheal intubation were included in the study after obtaining informed consent.

\section{Inclusion Criteria: -}

1. Either sex

2. ASA Grade I

3. Age between $20-45$ years

4. Weight between $35-80 \mathrm{kgs}$

\section{Exclusion Criteria:-}

1. ASA grade II, III \& IV

2. Age more than 45 years

3. Previous history of myocardial ischemia

4. History of Hypertension

5. History of CVA/ Eclampsia

\section{Preoperative period:-}

Pre-anaesthetic evaluation was done on the evening before surgery, routine investigations were done according to hospital protocol. All patients included in the study were premedicated with tablet Alprazolam $0.5 \mathrm{mg}$ orally at bed time the previous night before surgery. They were kept nil orally from $10 \mathrm{pm}$ onwards on the previous night.

\section{Allocation of the patients:-}

All the selected patients were allocated into three groups consisting of 25 patients each, using computer generated randomised table

- Group F- Received Fentanyl $2 \mu \mathrm{g} / \mathrm{kg}$ body weight.

- Group L- Received Lignocaine $1.5 \mathrm{mg} / \mathrm{kg}$ body weight.

- Group N- Received normal saline $3 \mathrm{ml}$ as placebo

\section{Intra operative period:-}

On arrival of the patient in the operating room, an 18-gauge intravenous cannula was secured over left forearm and an infusion of ringer lactate was started. Baseline monitoring was initiated with 5 lead ECG with monitoring lead II and $\mathrm{V}_{5}, \mathrm{NIBP}, \mathrm{SPO}_{2}$ and $\mathrm{ETCO}_{2}$. 


\section{Anaesthetic Procedure:-}

All the patients were pre-oxygenated with 100\% oxygen for 3 minutes using Closed circuit with a tight fitting facemask. Premedicated with inj. Glycopyrrolate $0.2 \mathrm{mg}$ IV, inj. Midazolam $1 \mathrm{mg}$ IV bolus and inj. Ondansetron $4 \mathrm{mg}$ IV.

Group- F: After pre-oxygenation, patients were pre-treated with I.V. Fentanyl $2 \mu \mathrm{g} / \mathrm{kg}$ injected slowly over 1 minute.

Group-L: After pre-oxygenation, patients were pre-treated with I.V. Lignocaine $1.5 \mathrm{mg} / \mathrm{kg}$ injected slowly over 1 minute

Group-N: After pre-oxygenation I.V. normal saline $3 \mathrm{ml}$ is injected

Induction agent of choice was I.V. 2.5\% Thiopentone $5 \mathrm{mg} / \mathrm{kg}$ and muscle relaxant used was I.V. succinylcholine 2 $\mathrm{mg} / \mathrm{kg}$. As soon as muscle fasciculation passed off and jaw was relaxed, laryngoscopy was performed with Macintosh curved blade and the appropriate sized endotracheal tube was passed. Heart rate, blood pressure, $\mathrm{SPO}_{2}$ was recorded just prior to the intubation (Baseline), at the time of intubation ( 0 minute) and over the next 5 minutes at an interval of 1,2,3,4 and 5 minutes following intubation.

All patients were ventilated with $2 \mathrm{~L} / \mathrm{min}$ of oxygen and $2 \mathrm{~L} / \mathrm{min}$ of nitrous oxide with the use of closed circuit. No additional agents were given for the first five minutes post-intubation, nor was any surgical stimulus given to these patients. Further anaesthesia in all three groups of patients was carried out as per the requirement of the patient. All patients who required a second attempt for intubation were excluded from the study.

\section{Analysis of Data:-}

Variables were analyzed for statistical significance using SPSS version 17.0. $\mathrm{p}$ value $<0.05$ and $\mathrm{p}$ value $<0.001$ were considered as statistically significant, and highly significant respectively.

\section{Results and Analysis:- \\ Demographic data:-}

The groups were comparable with respect to age, gender and weight. Mean age of the patients in groups F, L, N were $33.20 \pm 7.36,32.32 \pm 7.72$ and $34.88 \pm 6.31$ years respectively. Mean weight in groups F, L, N were 54 \pm 4.92 , $56 \pm 6.93$ and $53.20 \pm 5.20 \mathrm{kgs}$ respectively.

Heart Rate Response:- Changes in heart rate are mentioned in Table 1.

Table 1:- Changes In Heart Rate (Beats/ Min).

\begin{tabular}{|c|c|c|c|c|c|c|c|c|}
\hline & & B & 0 & 1 & 2 & 3 & 4 & 5 \\
\hline \multirow[t]{2}{*}{ Group-F } & Mean & 80 & 83 & 80 & 86 & 85.2 & 83.84 & 82.40 \\
\hline & SD & 7.39 & 7.55 & 5.62 & 4.06 & 2.12 & 2.19 & 1.66 \\
\hline \multirow[t]{2}{*}{ Group-L } & Mean & 78 & 80.56 & 82 & 91 & 90.16 & 89.40 & 89 \\
\hline & SD & 2.36 & 1.96 & 1.91 & 2.94 & 2.48 & 2.36 & 2.33 \\
\hline \multirow[t]{2}{*}{ Group- N } & Mean & 84.08 & 89.92 & 94.36 & 99.32 & 101.6 & 94.88 & 90.08 \\
\hline & SD & 5.72 & 6.39 & 5.84 & 6.60 & 5.75 & 5.06 & 4.72 \\
\hline
\end{tabular}

$\mathrm{B}=$ Baseline, $0=$ Zero minute, $1=1^{\text {st }}$ minute, $2=2^{\text {nd }}$ minute, $3=3^{\text {rd }}$ minute, $4=4^{\text {th }}$ minute, $5=5^{\text {th }}$ minute,

$\mathrm{SD}=$ Standard Deviation

$>$ The Baseline (B) heart rate in all the groups were comparable among the three groups. Heart rate at ' $\mathrm{B}$ ' \& ' 0 ' time in group F \& L was statistically insignificant ( $p>0.05$ ). While among Group L \& N at Baseline and at ' 0 ' time $p<0.001$ which is significant, while in group $F \& N$ it is $p<0.05$ at ' $B$ ' and $p<0.001$ at ' 0 ' time.

$>$ At $1 \mathrm{~min}$ the mean heart rates were $80,82 \& 94.36$ with a standard deviations of 5.62, 1.91, and 5.84 in groups F, L \& N respectively. There was no significant difference between groups F \& L ( $>0.05)$, but there was highly significant difference between Group L \& N ( $<<0.001)$ and group F \& $N(p<0.001)$.

$>$ At $2^{\text {nd }}$ min the mean heart rates were $86,91 \& 99.32$ with a standard deviations of 4.06, 2.94 and 6.60 in groups $\mathrm{F}, \mathrm{L}$ and $\mathrm{N}$ respectively. At $3^{\text {rd }}$ minute the mean heart rates were $85.20,90.16$ and 101.60 with a standard deviations of $2.12,2.48$ and 5.75 in groups $\mathrm{F}, \mathrm{L}$ and $\mathrm{N}$ respectively. At $4^{\text {th }}$ minute mean heart rates were $83.84,89.40 \& 94.88$ with a standard deviations of $2.19,2.36$ and 5.06 in groups $\mathrm{F}, \mathrm{L}$ and $\mathrm{N}$ respectively. There was statistically highly significant difference between all the groups at $2^{\text {nd }}, 3^{\text {rd }}$ and $4^{\text {th }}$ minutes $(\mathrm{p}<0.001)$. 
At $5^{\text {th }}$ minute the mean heart rates were $82.40,89$ and 90.08 with a standard deviations of $1.66,2.33$ and 4.72 in groups $\mathrm{F}, \mathrm{L}$ and $\mathrm{N}$ respectively. There was statistically highly significant difference between the groups $\mathrm{F} \&$ $\mathrm{L}(\mathrm{p}<0.001)$ and groups $\mathrm{F} \& \mathrm{~N}(\mathrm{p}<0.001)$, but there was no significant difference between the groups $\mathrm{L} \& \mathrm{~N}$ $(\mathrm{p}>0.05)$.

Blood Pressure Response:-

Systolic Blood Pressure (SBP):- Changes in SBP are mentioned in Table 2.

Table 2:- Change in Systolic Blood Pressure (In mm Hg)

\begin{tabular}{|c|c|c|c|c|c|c|c|c|}
\hline & & B & 0 & 1 & 2 & 3 & 4 & 5 \\
\hline \multirow[t]{2}{*}{ Group- F } & Mean & 131.6 & 123.92 & 124.8 & 128 & 130 & 132 & 130 \\
\hline & SD & 3.83 & 3.63 & 3.11 & 3.65 & 3.42 & 2.38 & 2.89 \\
\hline \multirow[t]{2}{*}{ Group- L } & Mean & 131.20 & 123.84 & 128.52 & 138.08 & 144 & 140 & 132 \\
\hline & SD & 6.43 & 5.54 & 5.88 & 4.95 & 4.40 & 4.08 & 4.69 \\
\hline \multirow[t]{2}{*}{ Group-N } & Mean & 123.84 & 127.20 & 130.16 & 132.32 & 133.16 & 129.44 & 125.68 \\
\hline & SD & 7.06 & 5.55 & 5.23 & 4.82 & 3.62 & 4.44 & 5.00 \\
\hline
\end{tabular}

$\mathrm{B}=$ Baseline, $0=$ Zero minute, $1=1^{\text {st }}$ minute, $2=2^{\text {nd }}$ minute, $3=3^{\text {rd }}$ minute, $4=4^{\text {th }}$ minute, $5=5^{\text {th }}$ minute,

$\mathrm{SD}=$ Standard Deviation

- Systolic blood pressure at 'B' time in groups F \& L was statistically insignificant ( $p>0.05$ ), while in groups $F \&$ $\mathrm{N}$ and groups $\mathrm{L} \& \mathrm{~N}$ the difference was statistically significant $(\mathrm{p}<0.001)$. At ' 0 ' time just before intubation the systolic blood pressures in group F \& L were statistically insignificant ( $>0.05$ ), whereas in group $\mathrm{L} \& \mathrm{~N}$ and $\mathrm{F}$ $\& \mathrm{~N}$ it was statistically significant $(\mathrm{p}<0.05)$.

- At 1 minute, There was statistically no significant difference in systolic blood pressure among the L \& $\mathrm{N}$ but there was highly significant difference in group $\mathrm{F} \& \mathrm{~L}$ and group $\mathrm{F} \& \mathrm{~N}(\mathrm{p}<0.001)$.

- $\quad$ At $2^{\text {nd }}, 3^{\text {rd }}$ and $4^{\text {th }}$ minutes, there was statistically highly significant difference between groups $\mathrm{F} \& \mathrm{~L}(\mathrm{p}<0.001)$, groups L \& N ( $<<0.001)$ and groups $\mathrm{F} \& \mathrm{~N}(\mathrm{p}<0.001)$.

- At $5^{\text {th }}$ minute, there was statistically no significant difference in between group F \&L (p>0.05) and there was highly significant difference in group $\mathrm{L} \& \mathrm{~N}$ and group $\mathrm{F} \& \mathrm{~N}(\mathrm{p}<0.001)$.

Diastolic Blood Pressure (DBP):- Changes in DBP are mentioned in Table 3.

Table 3:- Change in Diastolic Blood Pressure (In $\mathrm{mm} \mathrm{Hg}$ ).

\begin{tabular}{|c|c|c|c|c|c|c|c|c|}
\hline & & B & 0 & 1 & 2 & 3 & 4 & 5 \\
\hline \multirow{2}{*}{ Group- F } & Mean & 77.68 & 78 & 78 & 81.52 & 84 & 81.52 & 77.84 \\
\hline & SD & 4.42 & 4.69 & 4.43 & 4.45 & 3.27 & 4.74 & 4.65 \\
\hline \multirow{2}{*}{ Group- L } & Mean & 82 & 79.96 & 88 & 92 & 86 & 82 & 82 \\
\hline & SD & 4.12 & 3.93 & 4 & 4.28 & 4.04 & 3.74 & 3.27 \\
\hline \multirow[t]{2}{*}{ Group- N } & Mean & 76.36 & 85.48 & 87.36 & 88.80 & 86.24 & 82.96 & 79.12 \\
\hline & SD & 4.59 & 5.52 & 5.19 & 5.26 & 5.93 & 4.55 & 4.87 \\
\hline
\end{tabular}

$\mathrm{B}=$ Baseline, $0=$ Zero minute, $1=1^{\text {st }}$ minute, $2=2^{\text {nd }}$ minute, $3=3^{\text {rd }}$ minute, $4=4^{\text {th }}$ minute, $5=5^{\text {th }}$ minute,

$\mathrm{SD}=$ Standard Deviation

$>$ At baseline (B), there was statistically significant difference in DBP among group F\& L ( $<<0.001$ ), $\mathrm{L}$ and $\mathrm{N}$ $(\mathrm{p}<0.001)$. But no significant difference among groups $\mathrm{F}$ and $\mathrm{N}(\mathrm{p}>0.05)$.

$>$ At zero minute, there was statistically no significant difference in DBP among group F and L ( $>0.05$ ), significant in groups $\mathrm{L} \& \mathrm{~N}(\mathrm{p}<0.001)$ but highly significant among groups $\mathrm{F}$ and $\mathrm{N}(\mathrm{p}<0.001)$.

$>$ At $1^{\text {st }}$ minute, there was no statistically significant difference in diastolic blood pressure among groups $\mathrm{L}$ and $\mathrm{N}$ ( $p>0.05$ ) but highly significant difference between group $\mathrm{F}$ and $\mathrm{L}(\mathrm{p}<0.001), \mathrm{F}$ and $\mathrm{N}(\mathrm{p}<0.001)$. At $2^{\text {nd }}$ minute, there was statistically highly significant difference between group $F \& L(p<0.001)$, groups $F \& N(p<0.001)$ and groups $\mathrm{L} \& \mathrm{~N}(\mathrm{p}<0.05)$. Whereas at $3^{\text {rd }}$ and $4^{\text {th }}$ minutes there was statistically no significant difference between the groups $(\mathrm{p}>0.05)$.

$>$ At $5^{\text {th }}$ minute there was statistically significant difference in diastolic blood pressures among the groups $\mathrm{F}$ and $\mathrm{L}$ $(\mathrm{p}<0.001)$, whereas there was highly significant difference in groups $\mathrm{L}$ and $\mathrm{N}(\mathrm{p}<0.05)$ and no significant difference between groups $\mathrm{F}$ and $\mathrm{N}(\mathrm{p}>0.05)$. 


\section{Fentanyl (Group F):-}

On Heart rate: There was rise of only 6 beats/ minute from the mean baseline ' $\mathrm{B}$ ' value after intubation and 7.5\% rise and receded after 5 minutes. When this rise is compared with the control (placebo group $\mathrm{N}$ ), it was insignificant, but it is clinically and statistically highly significant $(\mathrm{p}<0.001)$.

\section{On Systolic Blood Pressure:-}

There was rise in systolic blood pressure of $1 \mathrm{~mm} \mathrm{Hg}$ from the mean baseline values 'B' with $0.7 \%$ rise and receded to baseline value after 5 minutes. This was not at all significant when compared to control (placebo group $\mathrm{N}$ ) but clinically and statistically the difference is significant $(\mathrm{p}<0.001)$.

\section{On Diastolic Blood Pressure:-}

There was rise in diastolic blood pressure of $7 \mathrm{~mm} \mathrm{Hg}$ from mean baseline ' $\mathrm{B}$ ' value with $9 \%$ rise and receded to baseline value after 5 minutes. This was not significant when compared to control (placebo group $\mathrm{N}$ ) but it is clinically and statistically the difference is significant $(\mathrm{p}<0.001)$.

\section{Lignocaine (Group L):-}

On Heart Rate:-

There was rise of 13 beats/ minute after intubation from the mean baseline value and $16.66 \%$ rise and receded to baseline after 5 minutes. When the rise is compared with control (placebo group $\mathrm{N}$ ), it was not significant, but it is clinically and statistically highly significant $(\mathrm{P}<0.001)$.

\section{Systolic Blood Pressure:-}

There was rise in $13 \mathrm{~mm} \mathrm{Hg}$ of systolic blood pressure, the mean baseline 'B' value and $9.9 \%$ rise. This was not significant when the rise is compared to the control (Placebo group N), but it was clinically and statistically highly significant $(\mathrm{p}<0.001)$.

\section{Diastolic Blood Pressure:-}

There was $10 \mathrm{~mm} \mathrm{Hg}$ rise in diastolic blood pressure from the baseline ' $\mathrm{B}$ ' value and $12.19 \%$ rise. This was not significant when the rise is compared with the control group (placebo group $\mathrm{N}$ ), but it was clinically and statistically highly significant $(\mathrm{p}<0.001)$.

\section{Placebo (Group N):-}

On Heart Rate: The heart rate showed a rise of 17 beats/ minutes from the mean baseline value with a $20.21 \%$ rise after intubation. The rise was clinically significant. The rise receded to baseline after 5 minutes.

\section{Systolic Blood Pressure:-}

Systolic blood pressure showed a rise of $10 \mathrm{~mm} \mathrm{Hg}$ from the mean baseline value and $8.13 \%$ rise post intubation. This was clinically significant and it receded to baseline value after 5 minutes.

\section{Diastolic Blood Pressure:-}

Diastolic blood pressure showed a rise of $12 \mathrm{~mm} \mathrm{Hg}$ from mean baseline value and a $15.7 \%$ rise after intubation. The rise was clinically significant. It receded to baseline after 5 minutes.

\section{Discussion:-}

Fentanyl and Lignocaine have undergone many clinical trials in combination with other drugs in relation to attenuation of cardiovascular response to laryngoscopy and intubation.

Work in attenuation of cardiovascular response was first begun by $\mathrm{King}^{13}$ et al in 1951 . He studied the cardiovascular response to laryngoscopy and intubation by cyclopropane and diethyl ether. Various techniques have been used thereafter to obtund the increase in arterial blood pressure and heart rate following laryngoscopy and intubation. Present study was done to evaluate the efficacy of fentanyl and lignocaine Vs each other and Vs normal saline as placebo in attenuating the cardiovascular response.

N.Dahlgren and K. Messeter ${ }^{14}$ (1981) conducted a study in 15 patients scheduled for elective neurosurgery. All the patients were above 15 years of age and were divided into two groups. Group I received Fentanyl $5 \mu \mathrm{g} / \mathrm{kg}$, group II 
received placebo (Saline). After laryngoscopy and intubation, the blood pressure response is very high in the control group (by about $50 \mathrm{mmHg}$ ), while there was no significant rise in fentanyl group (by about $14 \mathrm{~mm} \mathrm{Hg}$ ). The change in heart rate in response to laryngoscopy and intubation followed the same pattern. In our study, fentanyl effectively blunts the systolic blood pressure response during laryngoscopy and intubation (only $0.3 \%$ increase from the base line value against $30.76 \%$ increase from the base line value in control group).

Flacke $^{15}$ et al (1985) have postulated that CVS depression after fentanyl is due to inhibition of central sympathetic outflow that is apart from analgesia or other sensory depressant effect of fentanyl. Some central cardiovascular regulatory mechanisms are opioid sensitive. Hypotension produced by Fentanyl was indirect in nature. Fentanyl also modulates nociceptive input and provides effective blunting of responses to laryngoscopy and intubation. But in our study, both Fentanyl and Lignocaine attenuates cardiovascular response to laryngoscopy and intubation. But Fentanyl attenuates better when compared with Lignocaine.

Helfman, Steven M, Gold, Martein ${ }^{16}$ et al of University of Miami school of Medicine (1990) selected 80 patients and divided into 4 groups of 20 each to know which drug prevents tachycardia with hypertension associated with tracheal intubation. Patients received placebo, lidocaine $200 \mathrm{mg}, 200 \mu \mathrm{g}$ fentanyl and Esmolol $150 \mathrm{mg}$ IV respectively according to their corresponding group. After laryngoscopy and intubation increase in HR and systolic BP was observed in placebo group. In group IV who had received Esmolol showed significant decrease in heart rate and systolic BP when compared with placebo and either group. In all the three groups except placebo decrease in systolic blood pressure was observed but there is no significant difference between the groups. In our study also, with fentanyl attenuation of heart rate, blood pressure changes were significant and with lignocaine HR \& BP were significantly attenuated but to a lesser extent than fentanyl group.

Sam Chung K, Sinatra, Raymond $S^{17}$ et al (1991) conducted randomized double blind study to compare the ability of combination of fentanyl and Esmolol to blunt the hemodynamic effects of intubation with that of either agent alone. The maximum percent change from baseline heart rate was less in the $\mathrm{F}_{2} / \mathrm{E}_{2}$ and $\mathrm{F}_{5}$ groups $(12 \%$ and $16 \%$ respectively), the maximum percent change from baseline systolic blood pressure in the $F_{2} / E_{2}$ and $F_{5}$ group (15\% and $6 \%$ respectively). Here the heart rate response and $\mathrm{BP}$ response were effectively blunted by combination of fentanyl and Esmolol (low dose) and F5 group who had received $5 \mu \mathrm{g} / \mathrm{Kg}$ fentanyl. In our study we also observed, fentanyl blunts, the heart rate, blood pressure response to laryngoscopy and intubation effectively.

J.E. Smith, M.K. King, K.A. Pottinger ${ }^{18}$ et al (1992) in their study, they compared fiber optic intubation with fentanyl $(6 \mu \mathrm{g} / \mathrm{kg})$ and without fentanyl and traditional Macintosh intubation with fentanyl. Fentanyl attenuates the pressor response to fiber optic as well as Macintosh intubation under GA. In our present study fentanyl attenuated the BP response effectively during laryngoscopy and intubation.

\section{Conclusion:-}

In conclusion, the present study confirms that Fentanyl attenuates both the heart rate and blood pressure responses effectively to direct laryngoscopy and intubation, whereas with Lignocaine blood pressure was effectively controlled than heart rate.

\section{References:-}

1. Reid LC, Brace DE. Irritation of the respiratory tract and its reflex effect upon heart. Surg Gynaec \& Obst. 1940; 70:157-62.

2. Gupta S, Tank P. A comparative study of efficacy of esmolol and fentanyl for pressure attenuation during laryngoscopy and endotracheal intubation. Saudi J Anaesth. 2011; 5 (1):2-8. Jan-Mar.

3. Stoelting RK. Circulatory changes during laryngoscopy and tracheal intubation: Influence of duration of laryngoscopy with or without prior lidocaine. Anaesthesiology. 1977; 47:381-3.

4. Scheinin B, Scheinin M, Vuorinen J, Lindgren L. Alfentanil obtund the cardiovascular and sympathoadrenal responses to suxamethonium facilitated laryngoscopy and intubation. Br Jr Anesth.1989; 62:385-92.

5. Gopinath R, Thota S. Nifedipine to attenuate cardiovascular responses to endotracheal intubation. J Anaesth Clin Pharmacology. 1989; 5:99.

6. Stoelting RK. Attenuation of blood pressure to laryngoscopy and tracheal intubation with sodium nitroprusside. Anaesth Anal. 1979; 58:116. 
7. Davidson JA, Gilliespsie JA. Tracheal intubataion after induction of anesthesia with propofol, Alfentanil and i.v. lignocaine. Br J Anaesth. 1993; 70:163-6.

8. Davis MJ, Cronin KD, Cowie RW. The prevention of hypertension at intubation: a controlled study of intravenous hydralazine on patients undergoing intracranial surgery. Anaesthesia. 1981; 36:147.

9. Stoelting RK. Blood pressure and heart rate changes during short duration laryngoscopy for tracheal intubation: Influence of viscous or i.v. lidocaine. Anaesth Analg. 1978; 57:197-9.

10. Bachofen M. Suppression of blood pressure increases during intubation: Lidocaine or fentanyl? Anesthetist. 1988; 37(3):156-61.

11. Butterworth JF, Struchartz GR. Molecular mechanisms of local anesthesia: a review. Anesthesiology.1990; 72:711-734.

12. Collins VJ. 3rd Edn. Philadelphia: Lea and Febiger; 1993. Principles of anesthesiology, general and regional anesthesia. Vol.I and II.

13. King B.D., Harris L.C., Greifenstein F .E., Elder J.D., and Dripps R.D., Reflex circulatory responses to direct laryngoscopy and tracheal intubation performed during general anaesthesia; Anaesthesiology: 1951: 12:556-66.

14. Dahlgren N., and Messeter K., Treatment of stress response to laryngoscopy an intubation with fentanyl: Anaesthesia: 1981:36:1022-26.1

15. Flacke JW, David U, Flacke WE et al: Effects of fentanyl and diazepam in dogs deprived of autonomic tone. Anesth Analg 64-1053, 1985

16. Helfmann, Steven, Gold, Martin: Which drug prevents tachycardia \& hypertension associated with tracheal intubation? (Placebo, lidocaine, Fentanyl, Esmolol): Anaesthesia, Analgesia Apr-91, Vol: 72, No: 4.

17. Samchung.K, Sinatra, Raymond S, Halevy: Comparative study-ability of a combination of Fentanyl \& Esmolol to blunt the hemodynamic effects of intubation with that of either agent alone. Oct -92, Vol: 39, No: 8.

18. J E. Smith, M.J.King, H.F. Yanni, K.A. Pottinger effects of fentanyl on the circulatory responses to orotracheal, fibreoptic intubation: Anaesthesia -92. 